\title{
๖Observed Soil Moisture Impact on Strong Convection over Mountainous Tibetan Plateau $\mathscr{O}$
}

\author{
E. J. Barton, ${ }^{a}$ C. M. TAylor,,${ }^{\mathrm{a}, \mathrm{b}}$ C. Klein, ${ }^{\mathrm{a}, \mathrm{c}}$ P. P. Harris, ${ }^{\mathrm{a}}$ And X. MenG ${ }^{\mathrm{d}}$ \\ ${ }^{\text {a }}$ U.K. Centre for Ecology and Hydrology, Wallingford, United Kingdom \\ ${ }^{\mathrm{b}}$ National Centre for Earth Observation, Wallingford, United Kingdom \\ ${ }^{\mathrm{c}}$ Institute of Atmospheric and Cryospheric Sciences, University of Innsbruck, Innsbruck, Austria \\ ${ }^{\mathrm{d}}$ Department of Plateau Atmospheric Physics Research, Northwest, Institute of Eco Environment and Resources, \\ Chinese Academy of Sciences, Beijing, China
}

(Manuscript received 2 June 2020, in final form 14 October 2020)

\begin{abstract}
Convection over the Tibetan Plateau (TP) has been linked to heavy rain and flooding in downstream parts of China. Understanding processes which influence the development of convection on the TP could contribute to better forecasting of these extreme events. TP scale $(\sim 1000 \mathrm{~km})$ soil moisture gradients have been shown to influence formation of convective systems over the eastern TP. The importance of smaller-scale $(\sim 10 \mathrm{~km})$ variability has been identified in other regions (including the Sahel and Mongolia) but has yet to be investigated for the TP. In addition, compared to studies over flat terrain, much less is known about soil moisture-convection feedbacks above complex topography. In this study we use satellite observations of cold cloud, land surface temperature, and soil moisture to analyze the effect of mesoscale soil moisture heterogeneity on the initiation of strong convection in the complex TP environment. We find that strong convection is favored over negative (positive) land surface temperature (soil moisture) gradients. The signal is strongest for less vegetation and low topographic complexity, though still significant up to a local standard deviation of $300 \mathrm{~m}$ in elevation, accounting for $65 \%$ of cases. In addition, the signal is dependent on background wind. Strong convective initiation is only sensitive to local (tens of kilometers) soil moisture heterogeneity for light wind speeds, though large-scale (hundreds of kilometers) gradients may still be important for strong wind speeds. Our results demonstrate that, even in the presence of complex topography, local soil moisture variability plays an important role in storm development.
\end{abstract}

KEYWORDS: Asia; Atmosphere-land interaction; Convective storms; Mesoscale processes; Orographic effects; Soil moisture

\section{Introduction}

The Tibetan Plateau (TP) is the highest and most extensive plateau in the world, profoundly affecting climate and weather in the region (Yang et al. 2013; Li et al. 2014). Due to its average elevation of more than $4000 \mathrm{~m}$, it provides strong thermal and dynamical forcing in the midtroposphere during the summer months, fostering the frequent development of intense storms (e.g., Yang et al. 2004). Tibetan convective systems (TCSs) can be associated with particularly extreme rainfall events and contribute up to $\sim 70 \%$ of rainfall over the TP and adjacent areas (Hu et al. 2016). In particular, propagation of TCSs can bring heavy rain and flooding to downstream parts of China, affecting millions of people (e.g., Li et al. 2008; Zhao et al. 2019). A better understanding of the processes that impact TCS genesis over the TP could contribute to better forecasting of these extreme events. Furthermore, there is strong evidence for accelerated climate warming on the TP

¿ Denotes content that is immediately available upon publication as open access.

Supplemental information related to this paper is available at the Journals Online website: https://doi.org/10.1175/JHM-D-200129.s1.

Corresponding author: Emma J Barton,emmbar@ceh.ac.uk (e.g., Guo and Wang 2012; Duan and Xiao 2015). This warming may affect convection on the TP, and hence hazardous weather in China, which makes the identification of factors for TCS development even more important.

Numerous works have analyzed characteristics of TCSs using various satellite products (e.g., Guo et al. 2006; Li et al. 2008; $\mathrm{Hu}$ et al. 2016; $\mathrm{Li}$ et al. 2019; Gao et al. 2019). These studies have revealed two core regions for convective activity during the monsoon season, the southern-central plateau and the eastern plateau. The high frequency of TCSs over the southern-central plateau has been attributed to topography (Kurosaki and Kimura 2002; Barros et al. 2004; Fujinami et al. $2005)$. Large-scale $(>100 \mathrm{~km})$ mountain ranges have an organizing effect on afternoon strong convection. However, the correlation between cloud distribution and topography with horizontal scales of less than $100 \mathrm{~km}$ is less obvious (Kurosaki and Kimura 2002). Indeed, that study suggested that, at the mesoscale, the spatial distribution of cloud may be controlled by local thermally induced circulations.

Sugimoto and Ueno (2010), using a combination of satellite observations and model simulations, have demonstrated that the high frequency of TCSs over the eastern plateau is linked to a longitudinal surface wetness gradient. Sub-plateau-scale convergences are established by plateau scale heating contrasts,

This article is licensed under a Creative Commons Attribution 4.0 license (http://creativecommons.org/ licenses/by/4.0/).

DOI: 10.1175/JHM-D-20-0129.1 
(a)

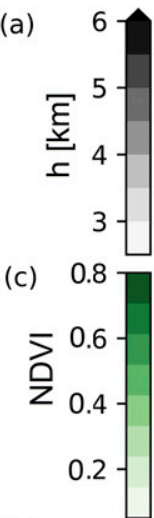

(e)

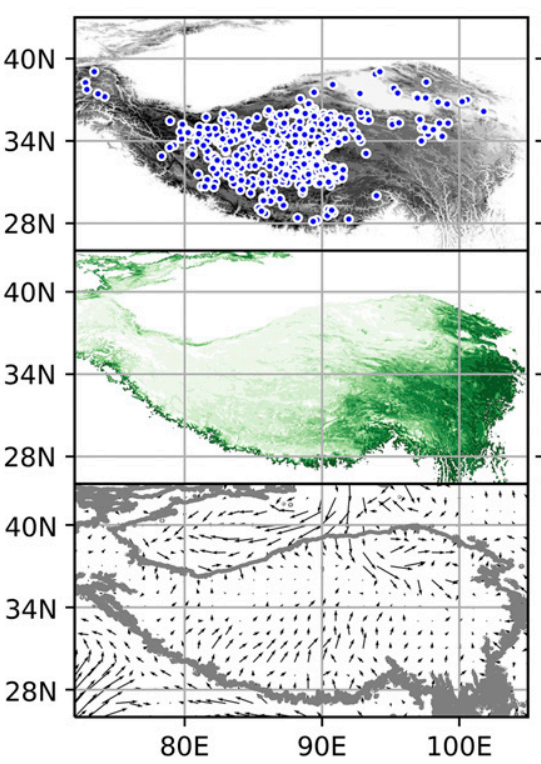

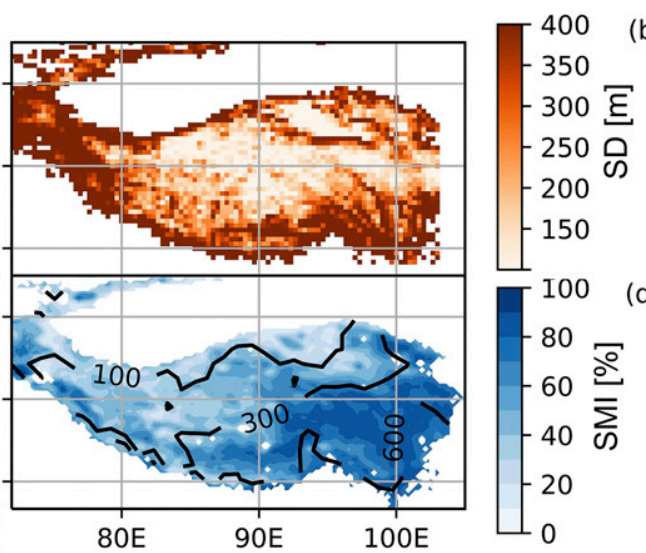

$3 \mathrm{~ms}^{-1}$ (b)

\section{它}

d) 
(NDVI), SM, and rainfall total occurring in the southeastern plateau (Figs. 1c,d).

\section{b. Datasets}

The datasets used in the current work are described in detail in this section and summarized in Table S1 in the online supplemental material. Topographic variability is computed from the Shuttle Radar Topography Mission 1 arc second global dataset (SRTM; Farr et al. 2007), vegetation state is interpreted from the MODIS TerralAqua monthly NDVI product at $0.05^{\circ}$ (MOD13C2/MYD13C2; Didan 2015a,b) and the location and size of lakes (with area $>10 \mathrm{~km}^{2}$ ) are taken from Wan et al. (2017).

Strong convection is identified from the Fengyun-2 (FY2) CTT product (NSMC 2013). FY2 is a series of geostationary satellites located at $0^{\circ}, 79^{\circ}-112^{\circ} \mathrm{E}$. The CTT product is available from 2013 to present and provides hourly (half-hourly for 2019 onward) images at $\sim 5-\mathrm{km}$ resolution. We use data from FY2F (2013-15), FY2G (2016-18), and FY2H (2019). For each year we selected data from the most recently launched satellite because of (i) the improved data continuity of $F Y 2 G$ compared to $F Y 2 F$ and (ii) the higher temporal resolution of $F Y 2 H$ compared to $F Y 2 G$. To ensure consistency between satellites we inspect images from years with more than one satellite. For $F Y 2 H / F Y 2 G$, coincident observations produce the same results in our identification of strong convective initiation (see section $2 \mathrm{c}$ ). For $F Y 2 G / F Y 2 F$ it is not possible to do a direct comparison due to a change in observation time (from $30 \mathrm{~min}$ past the hour to on the hour). However, the evolution of the cloud field in multisatellite simulations appears consistent. Due to the large viewing angles of the satellites it is necessary to correct for parallax. For the correction, cloud-top height is estimated using lapse rates from ERA5 reanalysis $\left(0.25^{\circ}, 1\right.$-h time step; Hersbach et al. 2019). Wind vectors at $10 \mathrm{~m}$ from ERA5 are also used to determine the direction and speed of background wind. Winds on the TP are highly variable in space, and the observational network is sparse. We therefore test the sensitivity of our results to the choice of wind reanalysis product, with parts of our analysis repeated using MERRA2 $\left(0.5^{\circ} \times 0.625^{\circ}, 1\right.$-h time step; Gelaro et al. 2017) and ERAInterim $\left(0.75^{\circ}, 6\right.$-h time step; Berrisford et al. 2011). To assess the statistical relationship between CTT and rainfall intensity we employ instantaneous radar measurements of surface rainfall rate from TRMM (2013, TRMM_2A25; TRMM 2011a) and GPM (2014-19; GPM_2ADPR; Iguchi and Meneghini 2017).

Prestorm surface wetness conditions are characterized from satellite observations of LST and SM. Due to the higher quality of LST observations (lower uncertainties, less missing data) compared to SM, the bulk of our analysis uses LST. Previous works (e.g., T11; T15) have used LST anomalies (LSTAs) as a proxy for surface wetness conditions. Locally positive (negative) LSTAs are indicative of locally drier (wetter) conditions compared to the surroundings. This study employs LSTA observations from the 10-km AMSR2 downscaled LPRM Level 2 product (overpass time $1530 \mathrm{LT}$, UTC +8 ; de Jeu and Owe 2014; Owe et al. 2008). The microwave radiometer provides all-sky observations; however, the $36.5-\mathrm{GHz}$ channel used for LST retrieval is sensitive to rain droplets in the atmosphere
(Gao et al. 2008; Holmes et al. 2009). To minimize rainfall contamination, the dataset is filtered using GPM IMERG Level 3 high quality precipitation based on microwave-only data (including AMSR2 images; Huffman et al. 2019). All pixels with rainfall rates greater than $1 \mathrm{~mm} \mathrm{~h}^{-1}$ between 1500 and $1700 \mathrm{LT}(\mathrm{UTC}+8)$ are excluded. A monthly mean LST climatology per pixel is constructed for the period 2013-19 on the $10-\mathrm{km}$ grid from which daily LSTAs are computed. The AMSR2 LPRM product also includes SM observations; however, this dataset contains a discontinuity in 2016 affecting SM values globally (note this discontinuity is not present in the LST time series). Instead we utilize independent SM observations contained within the ESA Climate Change Initiative (ESA-CCI) SM version 03.3 daily $25-\mathrm{km}$ product (ESA-CCI C3S 2018). Although there are uncertainties and a large number of data gaps in the ESA-CCI product over the TP, there is a significant correlation between positive SM anomalies and observed precipitation in summer (Meng et al. 2018). However, the current application requires prestorm, rather than daily, SM values. Therefore pixels containing only midday (1230 LT, UTC + 8) ASCAT observations are extracted and filtered. Only pixels with the highest quality flag of 0 and no rainfall contamination are retained. The resulting dataset is relatively sparse but does contain sufficient information to test our interpretation of results based on LST. As for LST, we compute a 7-yr SM climatology from which daily SM anomalies (SMA) are calculated. An evaluation study of remotely sensed and reanalysis SM products found that variations in ASCAT SM correlated well with in situ measurements (Zeng et al. 2015). Positive (negative) ASCAT SMAs should therefore be representative of wetter (drier) soils.

\section{c. Identification of strong convective initiation locations}

We define the development of strong convection as a newly emergent, rapidly cooling contiguous cloud area less than $30 \mathrm{~km}$ across, with CTT less than $-54^{\circ} \mathrm{C}$. The coordinate of the coldest pixel within the cloud area (corrected for parallax) is taken as the initiation point. Previous works have used rapidly cooling CTTs to identify convective initiation (e.g., Morel and Senesi 2002; T15), and cloud areas with spatial scales smaller than $35 \mathrm{~km}$ have been identified as having an increased probability of being associated with deep convection (Klein et al. 2018). There is some disparity in the literature on the temperature threshold for strong convection over the TP. Even very recent studies (e.g., Liu et al. 2019; Li et al. 2019), which use the same observational data $(F Y 2)$, have opted for subtly different thresholds. The choices are $-54^{\circ} \mathrm{C}$ (e.g., Liu et al. 2019; Sugimoto and Ueno 2010; Guo et al. 2006), $-53^{\circ} \mathrm{C}$ (e.g., $\mathrm{Li}$ et al. 2008 ; $\mathrm{Hu}$ et al. 2016), and $-52^{\circ} \mathrm{C}$ (e.g., Li et al. 2019).

A comparison of contiguous cold cloud (FY2) larger than $350 \mathrm{~km}^{2}$ (following Klein et al. 2018) and coincident radar precipitation (TRMM_2A25 and GPM_2APDR) indicates that the probability of intense rain increases with decreasing CTT (Fig. 2). We therefore opt for the coldest threshold from the literature in our definition of strong convection. To minimize "false initiations," in other words the detection of preexisting cloud areas associated with propagating cold cloud, 


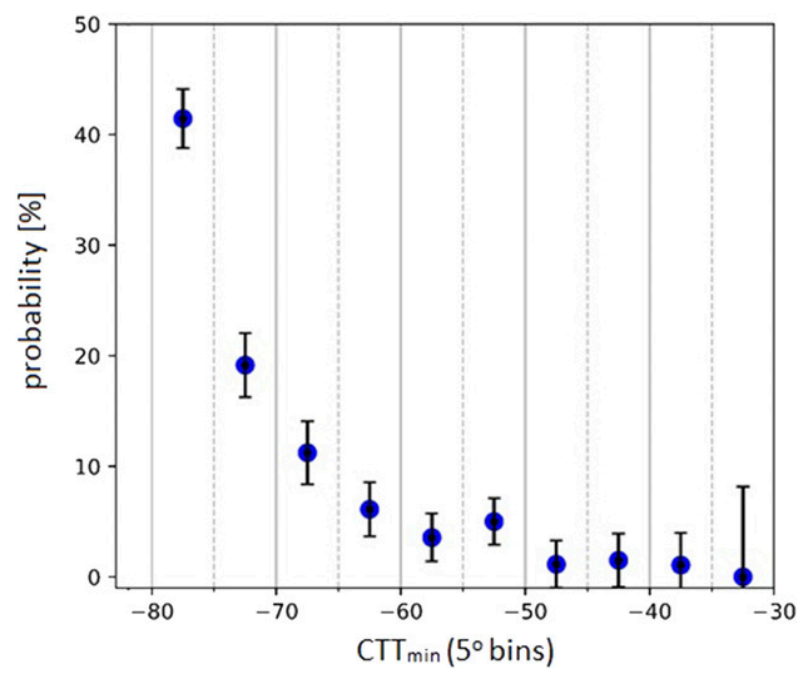

FIG. 2. Relationship of JJAS 2013-19 minimum cloud top temperature and probability for rainfall above $20 \mathrm{~mm} \mathrm{~h}^{-1}$ (99th percentile) per cloud. Error bars denote $2 \times$ standard error.

for each case we examine surrounding pixels within $50 \mathrm{~km}$ of the detected cloud area in the previous time step. We reject cases where the decrease in minimum CTT is less than $10^{\circ}$ over an hour (following T15).

On the TP it is vital to consider the impact of topography and lakes on the development of strong convection. To minimize the impact of lake triggers on our results, we exclude cases that occur within $20 \mathrm{~km}$ of water bodies greater than $10 \mathrm{~km}^{2}$ ( 20\% of cases are removed by this filter). The thresholds were chosen to maximize the number of retained cases while reducing the impact of lakes on the analysis. Increasing the proximity threshold to $50 \mathrm{~km}$ (as was done in T15) results in a large $(>50 \%)$ reduction in cases. Considering topography on the other hand, it is known from previous studies (e.g., Barros et al. 2004; Sugimoto and Ueno 2010; Li et al. 2019) that there is a higher frequency of convective activity over the southerncentral plateau, where topographic complexity is high. Rather than confine our analysis to relatively flat areas of the plateau, which would exclude this convective hotspot, we choose not to initially filter out cases in areas of strong topographic complexity. Instead we perform an additional analysis (described in section $3 b$ ) to explicitly examine the impact of topographic variability on the SM-convection coupling.

Figure 3 displays the 7-yr season mean spatial distribution and diurnal cycle of strong convective initiations (excluding lake cases) identified using our method for the entire season (JJAS). The same figures by month are provided in the supplemental material (Fig. S1). We observe the same core regions of convective activity as previous works, the southern-central and eastern plateau, although we find the former to be slightly stronger (Fig. 3a). This is similar to the findings of Li et al. (2019), who also used $F Y 2$ data to identify strong convection over the TP. We observe a peak in strong convective initiations in the afternoon (Fig. 3b), around 50\% of all storms form between the hours of 1400-2000 LT (0600-1200 UTC). This is similar to the diurnal cycle of summer TCS initiations reported
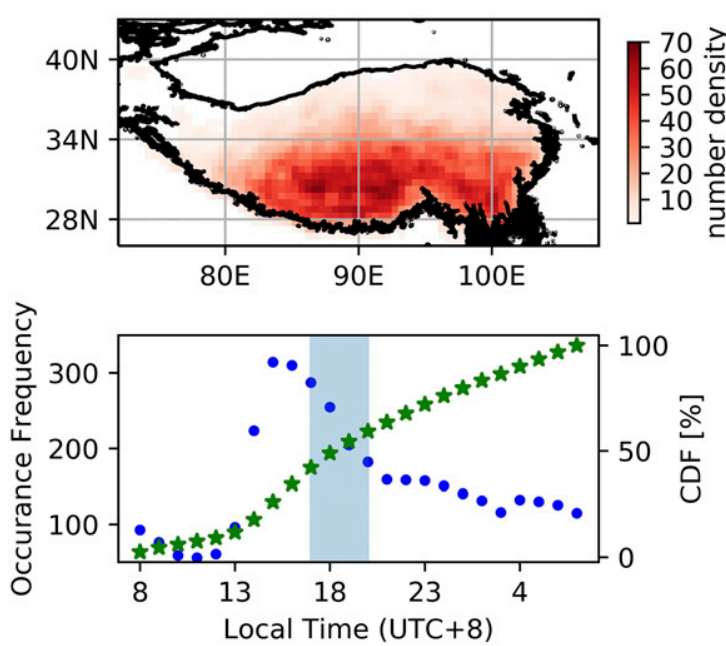

(b)

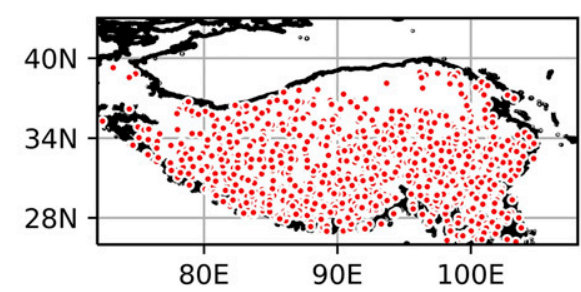

(c)

FIG. 3. Spatial and temporal properties of JJAS strong convective initiation. (a) The 7-yr mean occurrence frequency distribution calculated on a $0.5^{\circ} \times 0.5^{\circ}$ grid, (b) 7-yr mean diurnal cycle of occurrence frequency (circles) and cumulative distribution function (stars). The shaded area indicates the time period used in the analysis and (c) spatial distribution of strong convection cases used in the analysis.

by Li et al. (2008). To ensure we are sampling strong convection that initiated after our observations of LST (1530 LT, UTC + 8), we choose to focus our analysis on 1700-2000 LT (0900-1200 UTC), around $25 \%$ of all storms form between these hours (Fig. 3b). We assume these later storms have similar characteristics and formation mechanisms as those that develop earlier in the afternoon.

\section{d. Characterization of prestorm surface wetness}

To calculate mean prestorm surface wetness conditions we adopt the method used in T11 and T15. First, the initiation location for each strong convection case is matched to the closest grid point in the surface data (LSTA or SMA). A surface domain $( \pm 200 \mathrm{~km}$ relative to the initiation location) is then extracted and rotated in the direction of the background wind (using 10-m wind vectors from reanalysis). Finally, a composite of mean surface conditions is generated from an average of rotated surface domains for all cases. To ensure a fair comparison, the spatial mean LSTA/SMA is subtracted from the individual surface domains before averaging. It is necessary to consider the potential influence of missing data (particularly relevant for the SM data) on our mean surface composites. Therefore, to reduce the impact of sampling issues, we only include cases where the surface domain contains at least 50\% (75\%) valid AMSR2 (ASCAT) observations. 
Our resulting sample size is 1435 (172) strong convection initiation cases for LSTA (SMA).

\section{Results}

\section{a. Mean conditions}

First, we consider our full initiation sample to analyze the mean surface conditions associated with afternoon strong convection, presented in Fig. 4. The two-dimensional mean LSTA composite depicts a relatively warmer area upwind of the initiation location, with cooler conditions downwind (Fig. 4a). The preference for convection to develop on the downwind edge of dry patches, close to dry-wet boundaries, has been identified in modeling studies (e.g., Garcia-Carreras et al. 2011) and observed previously in the Sahel (T11) and Europe (T15). The two dimensional patterns of LSTA observed here show particular resemblance to the Sahel result, with positive anomalies over and upwind of the initiation location and negative anomalies around the edge of the domain.

Taking a downwind cross section through the center of the domain, we find the one dimensional LSTA gradient is strongest at and downwind of the initiation location (Fig. 4b). To assess the significance of the mean negative downwind LSTA gradient, we adopt the method from T15. For strong convection cases where there is sufficient local LSTA data, we sample an initiation gradient between -10 and $20 \mathrm{~km}$ (solid black rectangle in Fig. 4a, shading in Fig. 4b), corresponding to the scale around which we expect the effect of surface heterogeneity on initiations to be maximized (T11). Then, for the same cases, we sample up to eight non-initiation gradients (solid gray rectangles in Fig. 4a). These gradients are similarly computed over $30 \mathrm{~km}$ downwind using a linear regression (following T11/T15). Overall this gives us a set of $n_{i}=1194$ initiation gradients, with a mean of $-0.68 \mathrm{~K}(100 \mathrm{~km})^{-1}$, and $n_{\mathrm{ni}}=4071$ non-initiation gradients with a mean of $-0.02 \mathrm{~K}(100 \mathrm{~km})^{-1}$ (5265 gradients in total). To test whether the mean initiation gradient is significantly more negative than the mean noninitiation gradient, we perform a single-tail $p$ test on a distribution of random $D$ values, where $D$ is the difference between mean initiation and non-initiation gradients. This distribution is computed from 100000 random combinations of $n_{i}$ and $n_{\text {ni }}$ gradients from the pool of 5265 gradients (initiation plus non-initiation). Based on this test we find the mean initiation gradient to be statistically significant ( $p$ value of 0.02 ). Therefore, we can conclude that strong convection on the TP occurs preferentially over negative LSTA gradients.

To test the role of soil moisture conditions in creating observed LSTA patterns, we generate a mean SMA composite. A downwind cross section of mean composite SMA is presented in Fig. 4b. For the 30-km section over which initiation gradients are computed, downwind gradients in LSTA are anticorrelated with gradients in SMA, although the correlation is not consistent along the whole transect. This could be attributed to the limited number of valid pixels (only 172 cases with sufficient local SM data compared to 1435 cases for LST) and the lower spatial resolution of the SM product $(25 \mathrm{~km}$ for $\mathrm{SM}$ versus $10 \mathrm{~km}$ for LST). If we consider only the 172 cases with sufficient

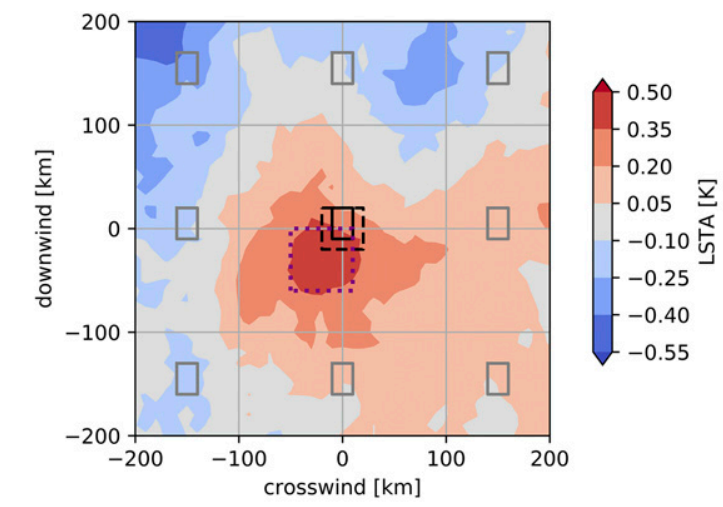

(a)

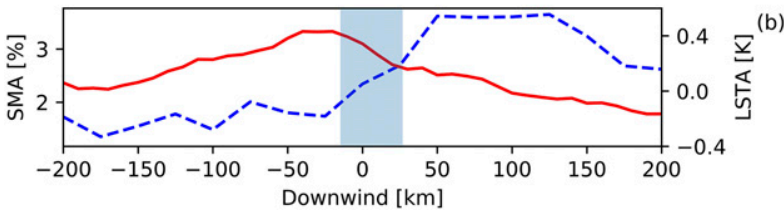

FIG. 4. (a) Composite mean LSTA (K; shading) for 1435 strong convection cases over the TP. For each case the LSTA data were orientated according to the low-level 1200 LT (0400 UTC) wind direction and regridded relative to the initiation location $(0,0)$. Black (gray) rectangles $(20 \mathrm{~km} \times 30 \mathrm{~km})$ with solid outlines indicate the zone(s) used to compute LSTA gradients for the initiation (noninitiation) sample. The black square with the dashed outline denotes the area $(40 \mathrm{~km} \times 40 \mathrm{~km})$ over which topographic complexity (standard deviation in elevation) is computed. The purple dotted square indicated the area sampled for the linear regressions described in the text. (b) Downwind cross sections of composite mean LSTA (K; solid red line) and SMA (\%; blue dashed line). The shaded section highlights the distance over which initiation gradients are computed.

local SM data, the two dimensional composites of SMA and LSTA have broadly similar structures (Fig. S2).

We also consider the potential role of preinitiation cloud cover on LSTA patterns. This is necessary since, in contrast to T11 and T15, the present study makes use of microwave LST observations, which provide data for both cloudy and cloud-free days. The LSTA signal may therefore be affected by variations in incoming shortwave radiation at the surface. Here we consider the 651 cases with $F Y 2$ cloud observations at time of the AMSR 2 overpass (1530 LT, UTC +8$)$. This is less than the total number of cases due to a change in satellite observation time (see section 2). For each pixel in the $400 \mathrm{~km} \times$ $400 \mathrm{~km}$ domain we determine the fraction of cases where cloud is present (according to FY2) and examine the resulting downwind cross section with comparison to mean composite LSTA (Fig. S3a). We observe slightly less cloud ( $\sim \%$ ) upwind of the initiation location coincident with warmer LSTA, which may be contributing to the observed LSTA gradient. To quantify the potential impact of this difference in cloudiness and surface insolation on our LSTA gradients, we first estimate relationships between LSTA and cloud cover fraction (CF) and SMA separately using linear regressions. Variables are sampled over the $50 \mathrm{~km} \times 50 \mathrm{~km}$ area of composite maximum positive LSTA (purple box with dotted outline in Fig. 4a). Mean LSTA and CF are sampled for the 651 cases with suitably timed cloud 


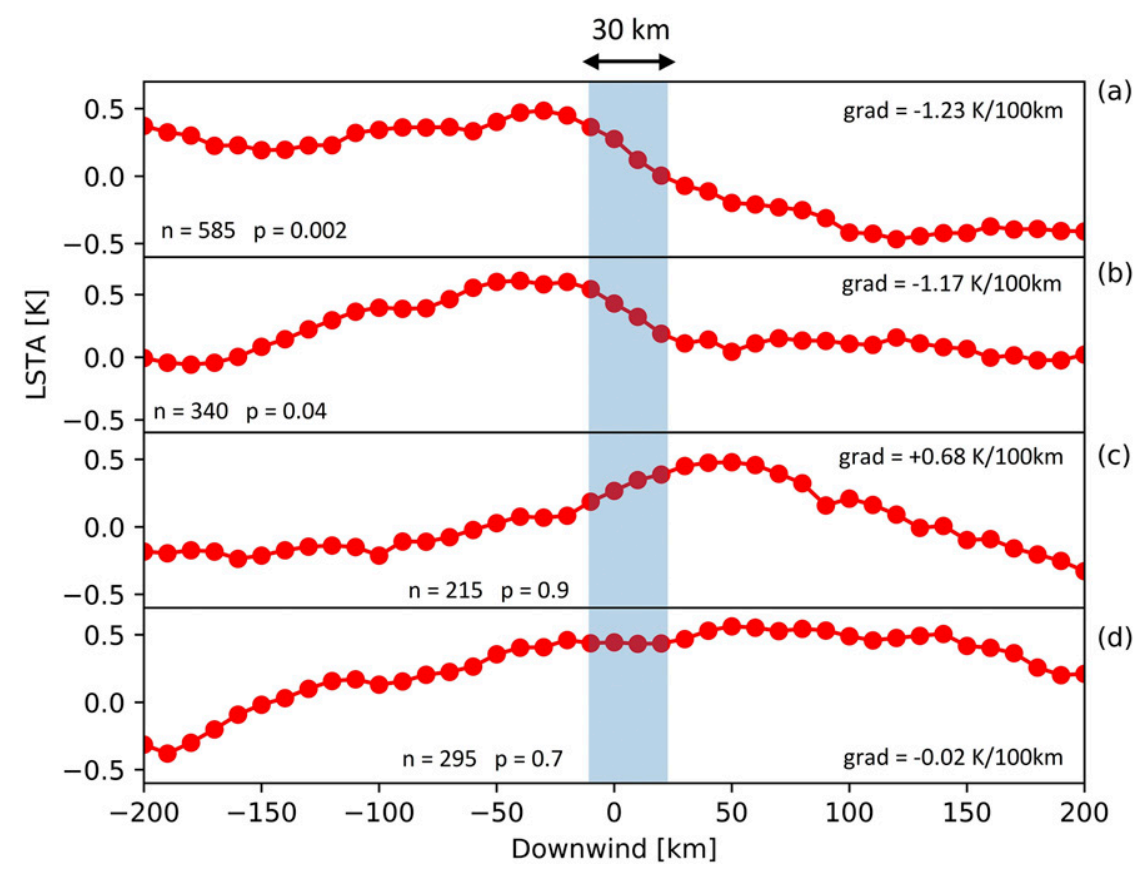

FIG. 5. Downwind cross sections of composite mean LSTA (K), where initiations have been divided into subsets by topographic complexity (standard deviation in elevation over a $40 \mathrm{~km} \times 40 \mathrm{~km}$ box): (a) <200, (b) 200-300, (c) 300-400, and (d) $>400 \mathrm{~m}$. Mean 30-km initiation gradients (grad), sample sizes $(n)$, and $p$ values are given for each subset. The $p$ values are determined from $n$ cases using the significance test described in section 3 a.

observations, while mean LSTA and mean SMA are sampled for the 172 cases with sufficient SM observations. In this instance CF is defined as the fraction of cloudy pixels in the $50 \mathrm{~km} \times 50 \mathrm{~km}$ area. As expected (Fig. S4), both drivers are negatively correlated with LSTA, though the variance explained by SMA $\left(r^{2}=27 \%\right)$ is more than twice as large as for CF $\left(r^{2}=12 \%\right)$. Using the slopes of these regression lines, we predict the magnitude of downwind LSTA variations induced by SM and cloudiness (Fig. S3b). The magnitude of the SMA derived signal (from 172 cases) is more than twice as large as the effect due to cloud variability and is consistent in both amplitude and location with the observed LSTA, which is based on 1435 cases.

Overall these tests indicate that SM, rather than cloudiness, is the dominant driver of our observed gradients in LSTA, though the impact of cloud variability likely reinforces the observed gradient.

\section{b. Dependence on topographic complexity}

On the TP, topography can help to mechanically lift unstable near-surface air, potentially triggering deep convection independently from SM states. During nighttime and morning hours, the fraction of initiation cases associated with high topographic complexity ranges between $39 \%$ and $45 \%$ (Fig. S5b). This decreases to $25 \%-37 \%$ in the afternoon, suggesting an increased importance of initiation mechanisms linked to surface heating.

To investigate the sensitivity of the all case signal to topographic complexity, we divide our sample into subsets according to the standard deviation in elevation computed over a $40 \mathrm{~km} \times 40 \mathrm{~km}$ box $(\mathrm{SD})$ centered on the initiation location (dashed box in Fig. 4a). The scale at which topographic complexity is considered was chosen to encompass the area within which initiation gradients are computed. Downwind cross sections are presented in Figs. 5a-d. Statistically significant $(p<0.05)$ negative downwind LSTA gradients are found for the two subsets with relatively modest topographic variability (SD less than $300 \mathrm{~m}$ ), corresponding to $65 \%$ of the total dataset (Fig. S5a). Changing the box size for the calculation of topographic complexity alters the magnitudes of SD and redistributes some of the cases. We find our chosen box size is more effective than larger box sizes at identifying cases where soil moisture is playing a significant role (Table S2). A weakening of the soil moisture signal with increasing topographic complexity is consistent with observations over East Mongolia (Teramura et al. 2019) and results from idealized model experiments (Imamovic et al. 2017).

\section{c. Sensitivity to background wind speed and dataset}

Background wind affects the persistence of surface-induced variability in the PBL and may change the propagation speed of initiated convection (Froidevaux et al. 2014). At the same time, wind speed and direction are variables difficult to correctly capture in reanalysis data for a complex region such as the TP (Yu et al. 2019). In the following, we therefore assess the sensitivity of our signal to wind conditions using three different reanalysis datasets.

To assess the impact of background wind speed on the SM-convection coupling signal, we consider only the 925 cases with relatively modest local topographic complexity $(\mathrm{SD}<300 \mathrm{~m})$, for which we found a significant relationship. This sample is 


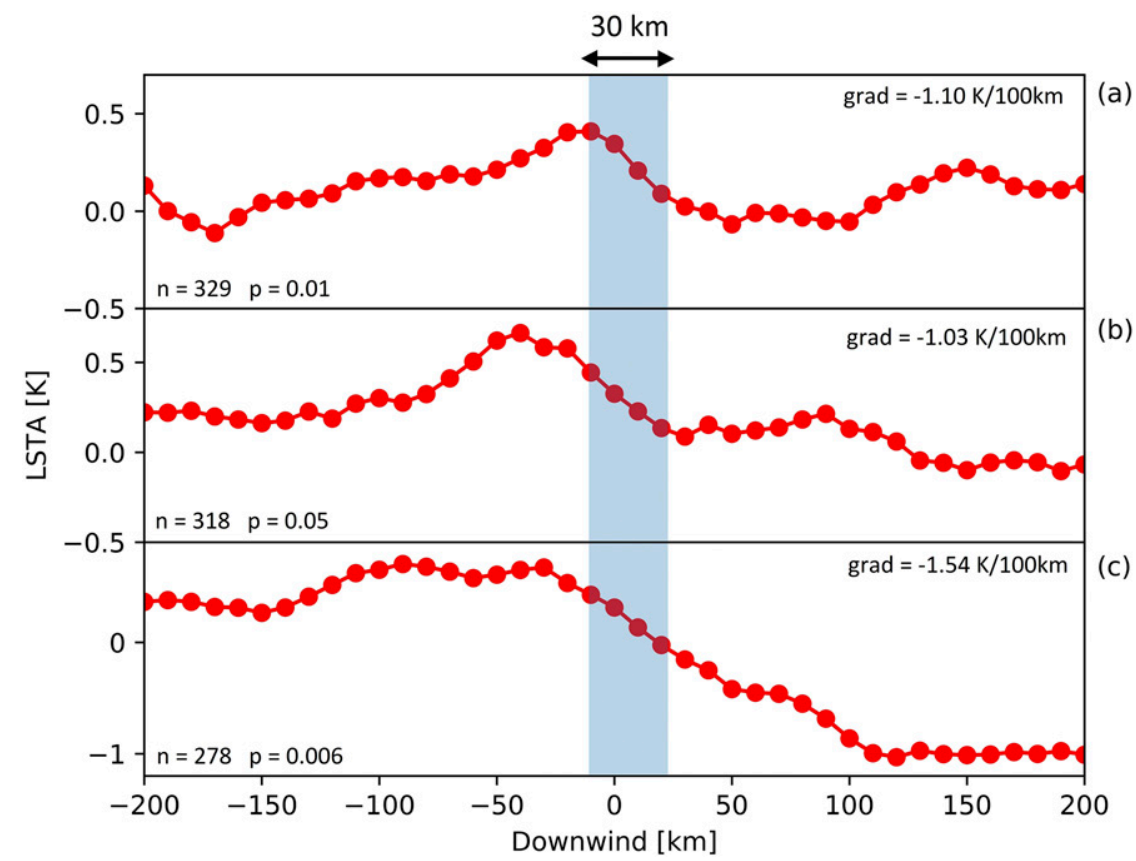

FIG. 6. Downwind cross sections of composite mean LSTA (K), where initiations have been divided into approximately equal-sized subsets by background wind conditions [ERA5 10-m wind speed sampled at 1200 LT (0400 UTC)] with high topographic complexity cases removed. Wind speeds in the three subsets are (a) $<1.6$, (b) $1.6-2.5$, and (c) $>2.5 \mathrm{~m} \mathrm{~s}^{-1}$. Mean $30-\mathrm{km}$ initiation gradients (grad), sample sizes $(n)$, and $p$ values are given for each subset. The $p$ values are determined from $n$ cases using the significance test described in section $3 \mathrm{a}$.

stratified into approximately equally sized subsets according to 1200 LT (0400 UTC) low-level wind speed using 10-m wind vectors from ERA5. Downwind cross sections are presented in Figs. 6a-c. Statistically significant $(p \leq 0.05)$ negative downwind LSTA gradients are found for all subsets; however, the length scale of the upwind warmer area appears to increase with increasing wind speed. A local $(30-50 \mathrm{~km})$ feature is only apparent for the two subsets with wind speeds lower than $2.5 \mathrm{~m} \mathrm{~s}^{-1}$. This is in agreement with results from large-eddy simulations which showed that wind speeds greater than $2.5 \mathrm{~m} \mathrm{~s}^{-1}$ suppressed the impact of surface heterogeneity on length scales up to $40 \mathrm{~km}$ (Avissar and Schmidt 1998). For high wind cases our results indicate that, although atmospheric sensitivity to small-scale heterogeneity (tens of kilometers) is suppressed, there is still a preference for convective initiation over larger scale (hundreds of kilometers) negative LSTA gradients.

To test the sensitivity of our results to the choice of reanalysis product, we recomputed the background wind speed subset (high topographic complexity cases removed) and all case LSTA composites using 10-m wind vectors from MERRA2 [0400 UTC (1200 LT)] and ERA-Interim [0600 UTC (1400 LT)]. Downwind cross sections are presented in Figs. 7a-d and mean $30-\mathrm{km}$ initiation gradients are presented in Table 1 . The one dimensional all case LSTA composites based on all three products are very similar (Fig. 7a) and the two dimensional composites also have consistent patterns (not shown). This gives us confidence that our mean result is not significantly impacted by uncertainties in modeled wind direction. For the background wind speed subset analysis, LSTA composites based on more recent products MERRA2 and ERA5 display similar behavior (Figs. 7b-d), particularly around the initiation location, although the initiation gradients derived from MERRA2 results are weaker and less significant (Table 1). In the case of ERA-Interim, the LSTA composites for moderate and high wind speeds display similar behavior to the MERRA2 and ERA5 results; however, this is not true for low wind speeds (Fig. 7b). This may be due to higher uncertainties in wind direction in the older model for this wind class. Stronger winds are more likely to be the result of persistent large-scale dynamical forcing, while lighter winds are more likely to be controlled by more rapidly evolving local drivers. The lower spatial and temporal resolution of ERA-Interim could mean the model is unable to accurately capture the latter. Indeed a global evaluation of daily averaged surface wind speeds found that ERA-Interim (along with two other reanalysis products with a 6-hourly time step) showed poor performance compared to an average of multiple reanalysis products (including ERA5 and MERRA2; Ramon et al. 2019). A comparison of wind direction between the products for our cases reveals a larger spread for lower wind speeds (Fig. S6), as expected. Both ERA-Interim and MERRA2 display a similar disagreement with ERA5, although we find the composite LSTA gradient to be more significant for MERRA2 than ERA-Interim ( $p=0.07$ and $p=0.6$ respectively, Table 1 ) suggesting there may be other factors contributing to the worse skill of ERA-Interim. Wind direction between the three products is most consistent 


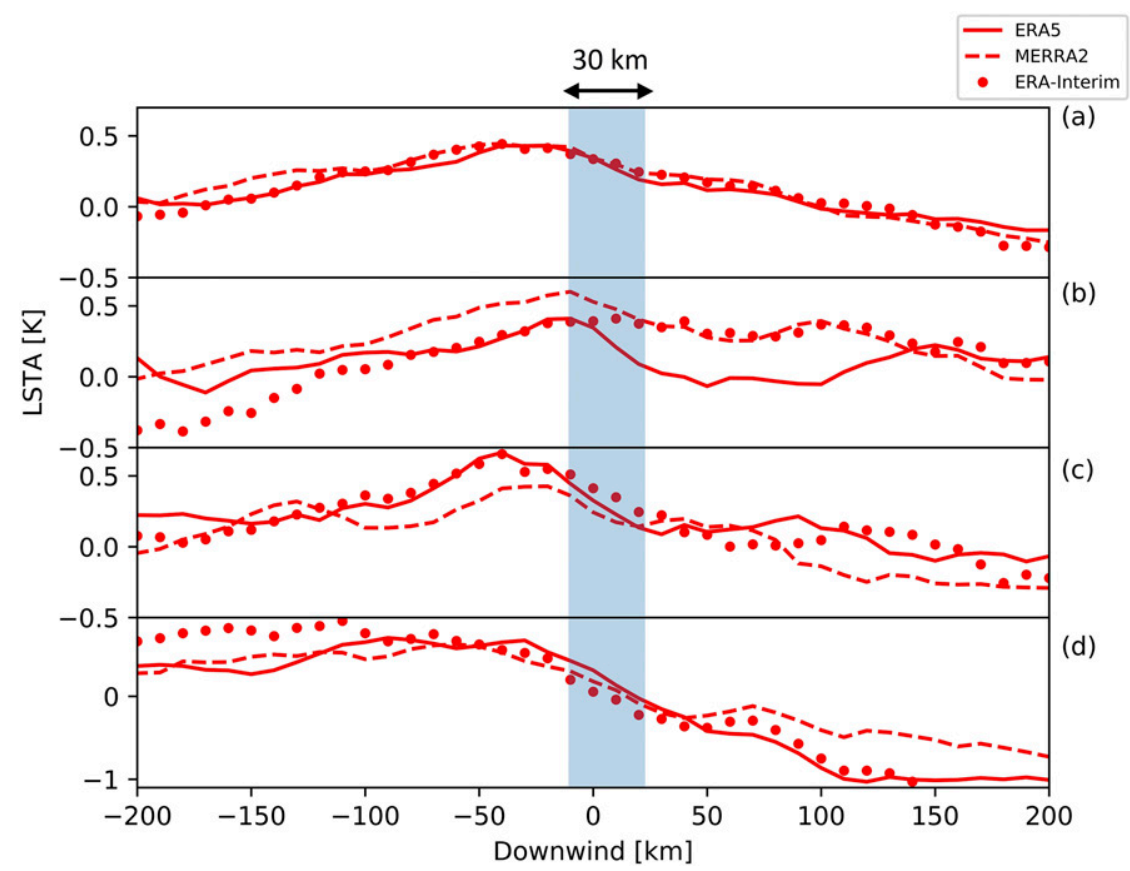

FIG. 7. Downwind cross sections of composite mean LSTA (K) computed using wind vectors from ERA5 [1200 LT (0400 UTC); solid line], MERRA2 [1200LT/ (0400 UTC); dashed line], and ERA-Interim [1400 LT (0600 UTC); dotted line]. For the wind speed subsets, high topographic complexity cases are removed then the sample is divided into approximately equally sized subsets by background wind speed. (a) All cases; (b) low wind speed subset, $s<1.6$ (ERA5), $s<2.7$ (MERRA2), or $s<2.4 \mathrm{~m} \mathrm{~s}^{-1}$ (ERA-Interim); (c) moderate wind speed subset, 1.6-2.5 (ERA5), 2.7-4.2 (MERRA2), or 2.4-3.6 $\mathrm{m} \mathrm{s}^{-1}$ (ERA-Interim); and (d) high wind speed subset, $s>2.5$ (ERA5), $s>4.2$ (MERRA2), or $s>3.6 \mathrm{~m} \mathrm{~s}^{-1}$ (ERA-Interim). Mean 30-km initiation gradients for each subset and product are given in Table 1.

for the high wind speed class, where we find significant largescale negative downwind LSTA gradients regardless of product used $(p \leq 0.05$, Table 1$)$.

\section{d. Impact of vegetation}

The presence of vegetation can suppress the impact of SM on surface flux partitioning and potentially weaken the coupling between SM and convection (Williams and Torn 2015). To determine the effect of vegetation on the local SMconvection coupling signal, we consider the 647 cases with relatively modest local topographic complexity $(\mathrm{SD}<300 \mathrm{~m})$ and lower background wind speeds $\left(s<2.5 \mathrm{~m} \mathrm{~s}^{-1}\right)$. This sample is divided into low and high vegetation classes of approximately equal size according to MODIS Terra/Aqua monthly
NDVI. Due to the northwest-southeast gradient in vegetation on the plateau, cases are broadly separated into groups of southeastern (high vegetation) and northwestern (low vegetation) storms (Fig. S7). Downwind cross sections are presented in Figs. $8 \mathrm{a}$ and $8 \mathrm{~b}$. The LSTA composites for both vegetation classes have similar characteristics around the initiation location, although the mean initiation gradient is $0.24 \mathrm{~K}(100 \mathrm{~km})^{-1}$ weaker for the high NDVI subset. This is consistent with SM controls on convection being more important in climatologically drier (less vegetated) environments. For example, numerical experiments have found that vegetation exerts a "homogenizing" effect on domain SM due to increased moisture uptake from the root zone in wetter areas (Ivanov et al. 2010). However, the significant LSTA gradient

TABLE 1. Reanalysis product comparison: downwind 30-km initiation gradients derived from mean LSTA composites.

\begin{tabular}{|c|c|c|c|c|c|c|c|c|c|}
\hline \multirow[b]{2}{*}{ Subset } & \multicolumn{3}{|c|}{ ERA5 } & \multicolumn{3}{|c|}{ MERRA2 } & \multicolumn{3}{|c|}{ ERA-Interim } \\
\hline & $\begin{array}{l}\text { Wind speed } \\
\left(\mathrm{m} \mathrm{s}^{-1}\right)\end{array}$ & $\begin{array}{c}\text { Gradient } \\
{\left[\mathrm{K}(100 \mathrm{~km})^{-1}\right]}\end{array}$ & $p$ value & $\begin{array}{l}\text { Wind speed } \\
\qquad\left(\mathrm{m} \mathrm{s}^{-1}\right)\end{array}$ & $\begin{array}{c}\text { Gradient } \\
{\left[\mathrm{K}(100 \mathrm{~km})^{-1}\right]}\end{array}$ & $p$ value & $\begin{array}{l}\text { Wind speed } \\
\left(\mathrm{m} \mathrm{s}^{-1}\right)\end{array}$ & $\begin{array}{c}\text { Gradient } \\
{\left[\mathrm{K}(100 \mathrm{~km})^{-1}\right]}\end{array}$ & $p$ value \\
\hline All case & - & -0.68 & 0.02 & - & -0.59 & 0.03 & - & -0.41 & 0.2 \\
\hline Low wind & $<1.6$ & -1.10 & 0.01 & $<2.7$ & -0.61 & 0.07 & $<2.4$ & -0.03 & 0.6 \\
\hline Moderate wind & $1.6-2.5$ & -1.28 & 0.05 & $2.7-4.2$ & -0.72 & 0.1 & $2.4-3.6$ & -0.86 & 0.2 \\
\hline High wind & $>2.5$ & -1.54 & 0.006 & $>4.2$ & -1.28 & 0.02 & $>3.6$ & -1.37 & 0.05 \\
\hline
\end{tabular}




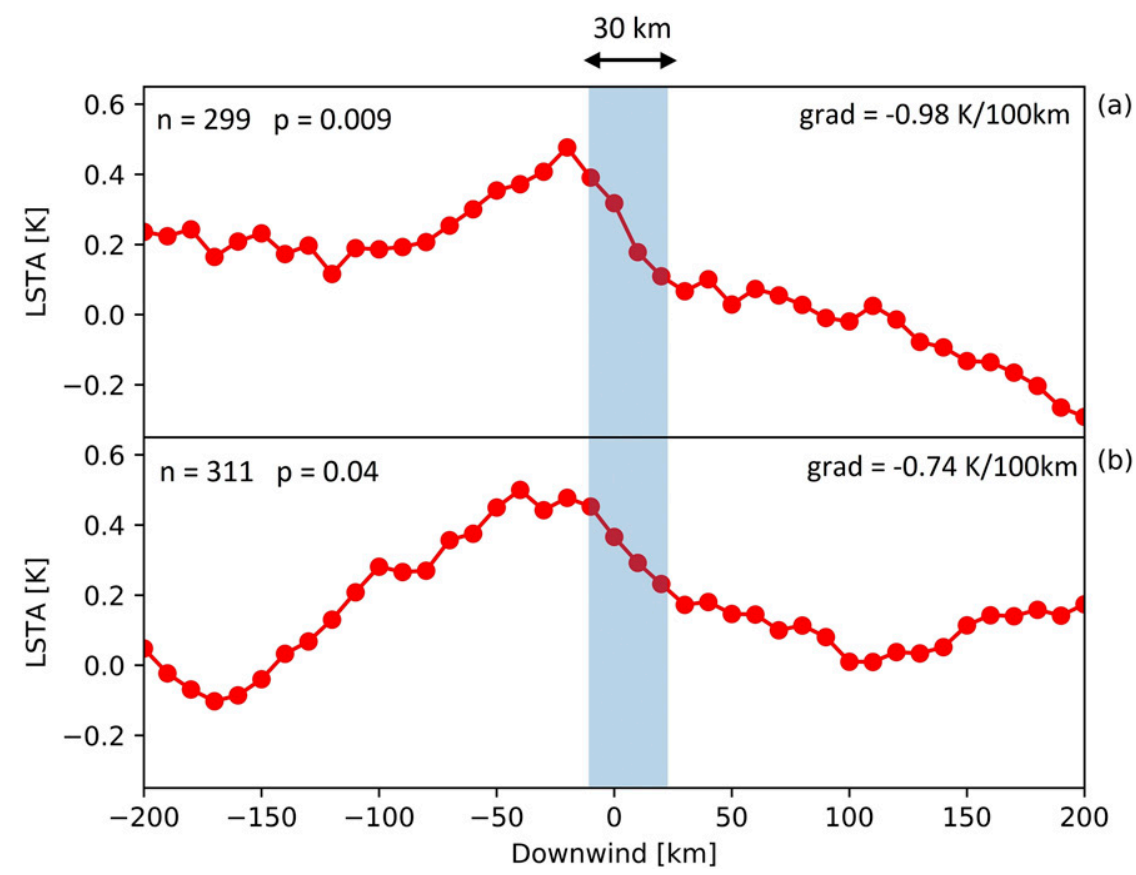

FIG. 8. Downwind cross sections of composite mean LSTA (K), where initiations have been divided into high and low vegetation classes by MODIS TerralAqua NDVI, with high topographic complexity and strong wind cases removed. (a) Low vegetation, NDVI $<0.25$ and (b) high vegetation, NDVI $>0.25$. Mean $30-\mathrm{km}$ initiation gradients (grad), sample sizes $(n)$, and $p$ values are given for each subset. The $p$ values are determined from $n$ cases using the significance test described in section 3 a.

even for high vegetation cases might be linked to the characteristics of TP vegetation types. Due to altitude and widespread grazing, alpine meadows and steppes dominate across our focus region (e.g., Pang et al. 2017; Zhong et al. 2010). Different from deep-rooted vegetation with high leaf area, like forests, evaporation from grass and shrub land is likely to correlate with top-level soil moisture on high spatial-temporal scales in water limited regions, as demonstrated for the TP by Cui et al. (2020) using laboratory measurements. It should also be noted that for a given SM induced gradient in sensible heat flux, denser (aerodynamically rougher) vegetation would produce a weaker LST gradient than a surface with more bare soil. Therefore we cannot conclude that the steeper LSTA gradient found in Fig. 8a is necessarily associated with a stronger sensible heat flux gradient. It is also worth noting that vegetation contrasts on the TP may have an effect on the timing of local convection (Babel et al. 2014), which will not be captured by the current analysis.

\section{Discussion}

This work reveals the influence of mesoscale SM heterogeneity on the initiation of strong convection over the TP. Using satellite observations we show a preference for strong convective development on the downwind side of dry surfaces, close to wetter areas, similar to results from Europe (T15) and West Africa (T11). The spatial relationship between surface gradients and convective initiation in these studies suggests that the preference for afternoon rain to occur over locally drier soils globally (Taylor et al. 2012) is related to surface-induced mesoscale circulations. However, the mean downwind LSTA gradient observed here for semiarid Tibet $\left[-0.68 \mathrm{~K}(100 \mathrm{~km})^{-1}\right]$ is more comparable to temperate Europe $\left[-0.58 \mathrm{~K}(100 \mathrm{~km})^{-1}\right]$ than semiarid West Africa $\left[-3.2 \mathrm{~K}(100 \mathrm{~km})^{-1}\right]$. This could be attributed to a number of factors.

First, over the mountainous TP, there are known orographic effects on strong convection (e.g., Kurosaki and Kimura 2002; Barros et al. 2004; Fujinami et al. 2005). In general, orographic effects on convective initiation are considered to be stronger than land surface heterogeneity effects (Houze 2012). For this reason, unlike the Europe study, we chose to explicitly analyze the impact of topography on our result. Consistent with expectations, our observed impact of local SM variability on the development of strong convection is moderated by local topographic complexity, as demonstrated by our subset analysis. The downwind LSTA gradient for the low topographic complexity subset $\left[-1.23 \mathrm{~K}(100 \mathrm{~km})^{-1}\right]$ is nearly double the mean gradient for all cases $\left[-0.68 \mathrm{~K}(100 \mathrm{~km})^{-1}\right]$.

Having an average elevation of $4000 \mathrm{~m}$ and "on plateau" mountain ranges, the atmospheric dynamics on the TP are significantly more complex than the Sahel. This is highlighted by the high sensitivity of our signal to background wind speed. It must be acknowledged that our subset analysis also displays a sensitivity to the choice of reanalysis product. However, all three sets of results show a change in surface gradient length scale with 
increasing wind speed, from tens of kilometers for lighter winds to hundreds of kilometers for stronger winds. This suggests that strong wind speeds have the effect of suppressing the impact of small-scale heterogeneity on convective initiation (consistent with numerical simulations; e.g., Avissar and Schmidt 1998), but larger-scale gradients may still be important in these cases. This result is different to both previous studies as no sensitivity to wind speed was found for the Sahel, and no significant relationship between gradients and initiations for high wind speeds was found in Europe.

There will likely be some uncertainty in the composites due to satellite product limitations. The TP is a challenging region of the world for remote sensing (e.g., Meng et al. 2018; Zeng et al. 2015). Although we have made special effort to retain only the highest quality observations by filtering the datasets (see section $2 b$ ), some errors may remain. This will include uncertainties in the measurements and potential misidentification of rain contaminated pixels. This work makes use of microwave LST observations that provide data for all-sky conditions, hence the measurements may be influenced by cloud cover. We observe a small sensitivity of our LSTA signal to variations in cloud cover, which will have increased the derived gradients. Also, our initiation locations are derived from hourly CTT data, whereas both T11 and T15 had 15 min observations available to them. The cloud field can evolve significantly in $1 \mathrm{~h}$, particularly if storms are moving quickly. This will undoubtedly compromise our ability to accurately map the location where rapid growth in convection first occurs, effectively introducing some spatial noise. In addition the LSTA gradients may be weaker for Tibet due to the limited time window within the diurnal cycle of convective initiations considered in our analysis (limited by our observations of LST). The fraction of initiations occurring over complex topography (SD $>300 \mathrm{~m})$ is smallest around $1400 \mathrm{LT}$ (28\% compared to the average $35 \%$ in our time window, Fig. S5b). This may suggest the impact of soil moisture (verse topography) on convective triggering is stronger earlier in the afternoon.

\section{Conclusions}

Our main conclusions may be summarized as follows:

1) As found in the Sahel, strong convection over the Tibetan Plateau is favored over negative (positive) land surface temperature (soil moisture) gradients.

New findings for Tibetan Plateau:

2) The signal is strongest for low topographic complexity, but still significant for local standard deviation in topography up to $300 \mathrm{~m}$.

3) The atmosphere is only sensitive to local (tens of kilometers) soil moisture heterogeneity under calm synoptic conditions (light background wind speeds).

4) Increased vegetation moderates the surface temperature gradients; however, the soil moisture-convective initiation coupling signal is still prevalent in these cases.

Our results demonstrate that, even in the complex TP environment, mesoscale variations in SM still play an important role in storm development. Models will not only need to capture the SM-convection feedback, but also its dependence on the highly varying TP surface and synoptic conditions.

Acknowledgments. This work and its contributors Barton, Taylor, and Harris were supported by the U.K.-China Research and Innovation Partnership Fund through the Met Office Climate Science for Service Partnership (CSSP) China as part of the Newton Fund. Meng was supported by the Chinese National Science Foundation Programs (41822501, 41930759). The authors thank the China Meteorological Administration National Satellite Meteorological Center for providing the Fengyun-2 cloud top temperature product. The authors declare no conflict of interest.

Data availability statement. Observational and reanalysis data used in this work can be downloaded from https:// satellite.nsmc.org.cn/ (Fengyun), https://disc.gsfc.nasa.gov/ (AMSR2, TRMM, GPM, IMERG, and MERRA2), https:/earthdata.nasa.gov/ (MODIS/AQUA NDVI), https://www.ecmwf.int/en/forecasts/ datasets/reanalysis-datasets/era-interim (ERA-Interim), and https:// cds.climate.copernicus.eu/ (ESA-CCI and ERA5).

\section{REFERENCES}

Avissar, R., and T. Schmidt, 1998: An evaluation of the scale at which ground-surface heat flux patchiness affects the convective boundary layer using large-eddy simulations. J. Atmos. Sci., 55, 2666-2689, https://doi.org/10.1175/1520-0469(1998) $055<2666$ :AEOTSA $>2.0 . \mathrm{CO} ; 2$.

Babel, W., and Coauthors, 2014: Pasture degradation modifies the water and carbon cycles of the Tibetan highlands. Biogeosciences, 11, 6633-6656, https://doi.org/10.5194/bg-116633-2014.

Barros, A. P., G. Kim, E. Williams, and S. W. Nesbitt, 2004: Probing orographic controls in the Himalayas during the monsoon using satellite imagery. Nat. Hazards Earth Syst. Sci., 4, 29-51, https://doi.org/10.5194/nhess-4-29-2004.

Berrisford, P., and Coauthors, 2011: The ERA-Interim Archive: Version 2.0. ERA Rep. Series 1, 23 pp., https://www.ecmwf.int/ sites/default/files/elibrary/2011/8174-era-interim-archiveversion-20.pdf.

Corsmeier, U., and Coauthors, 2011: Processes driving deep convection over complex terrain: A multi-scale analysis of observations from COPS IOP 9c. Quart. J. Roy. Meteor. Soc., 137, 137-155, https://doi.org/10.1002/qj.754.

Cui, J., L. Tian, Z. Wei, C. Huntingford, P. Wang, Z. Cai, N. Ma, and L. Wang, 2020: Quantifying the controls on evapotranspiration partitioning in the highest alpine meadow ecosystem. Water Resour. Res., 56, 1-22, https://doi.org/10.1029/ 2019WR024815.

de Jeu, R., and M. Owe, 2014: AMSR2/GCOM-W1 downscaled surface soil moisture (LPRM) L2B V001. GES DISC, accessed 1 January 2019, https://doi.org/10.5067/KZ9OOIENUO0C.

Didan, K., 2015a: MOD13C2 MODIS/Terra Vegetation Indices Monthly L3 Global 0.05Deg CMG V006. NASA EOSDIS Land Processes DAAC, accessed 1 April 2020, https://doi.org/ 10.5067/MODIS/MOD13C2.006.

_ 2015b: MYD13C2 MODIS/Aqua Vegetation Indices Monthly L3 Global 0.05Deg CMG V006. NASA EOSDIS Land Processes DAAC, accessed 1 April 2020, https://doi.org/ 10.5067/MODIS/MYD13C2.006. 
Duan, A., and Z. Xiao, 2015: Does the climate warming hiatus exist over the Tibetan Plateau? Sci. Rep., 5, 13711, https://doi.org/ 10.1038/srep13711.

Ek, M. B., and A. A. M. Holtslag, 2004: Influence of soil moisture on boundary layer cloud development. J. Hydrometeor., 5, 86-99, https://doi.org/10.1175/1525-7541(2004)005<0086: IOSMOB $>2.0 . \mathrm{CO} ; 2$.

ESA-CCI C3S, 2018: Soil moisture gridded data from 1978 to present. Copernicus Climate Change Service Climate Data Store (CDS), accessed 1 October 2019, https://cds.climate.copernicus.eu/ cdsapp\#!/home.

Farr, T. G., and Coauthors, 2007: The Shuttle Radar Topography Mission. Rev. Geophys., 45, RG2004, https://doi.org/10.1029/ 2005RG000183.

Findell, K. L., and E. A. Eltahir, 2003: Atmospheric controls on soil moisture-boundary layer interactions. Part I: Framework development. J. Hydrometeor., 4, 552-569, https://doi.org/ 10.1175/1525-7541(2003)004<0552:ACOSML > 2.0.CO;2.

Froidevaux, P., L. Schlemmer, J. Schmidli, W. Langhans, and C. Schär, 2014: Influence of the background wind on the local soil moisture-precipitation feedback. J. Atmos. Sci., 71, 782799, https://doi.org/10.1175/JAS-D-13-0180.1.

Fujinami, H., S. Nomura, and T. Yasunari, 2005: Characteristics of diurnal variations in convection and precipitation over the southern Tibetan Plateau during summer. SOLA, 1, 49-52, https://doi.org/10.2151/sola.2005-014.

Gao, G., Q. Chen, H. Cai, Y. Li, and Z. Wang, 2019: Comprehensive characteristics of summer deep convection over Tibetan Plateau and its south slope from the Global Precipitation Measurement Core Observatory. Atmosphere, 10, 9, https:// doi.org/10.3390/atmos10010009.

Gao, H., R. Fu, R. E. Dickinson, and R. I. NegrónJuárez, 2008: A practical method for retrieving land surface temperature from AMSR-E over the Amazon forest. IEEE Trans. Geosci. Remote Sens., 46, 193-199, https://doi.org/10.1109/TGRS.2007.906478.

Garcia-Carreras, L., D. J. Parker, and J. H. Marsham, 2011: What is the mechanism for the modification of convective cloud distributions by land surface-induced flows? J. Atmos. Sci., 68 , 619-634, https://doi.org/10.1175/2010JAS3604.1.

Gelaro, R., and Coauthors, 2017: The Modern-Era Retrospective Analysis for Research and Applications, version 2 (MERRA-2). J. Climate, 30, 5419-5454, https://doi.org/10.1175/JCLI-D-160758.1.

Gerken, T., W. Babel, M. Herzog, K. Fuchs, F. Sun, Y. Ma T. Foken, and H.-F. Graf, 2015: High-resolution modelling of interactions between soil moisture and convective development in a mountain enclosed Tibetan Basin. Hydrol. Earth Syst. Sci., 19, 4023-4040, https://doi.org/10.5194/hess-19-4023-2015.

Guo, D., and H. Wang, 2012: The significant climate warming in the northern Tibetan Plateau and its possible causes. Int. J. Climatol., 32, 1775-1781, https://doi.org/10.1002/joc.2388.

Guo, Z.-Y., X.-Y. Dai, J.-P. Wu, and H. Lin, 2006: Analysis of mesoscale convective systems over Tibetan Plateau in summer. Chin. Geogr. Sci., 16, 116-121, https://doi.org/10.1007/ s11769-006-0004-7.

Hauck, C., C. Barthlott, L. Krauss, and N. Kalthoff, 2011: Soil moisture variability and its influence on convective precipitation over complex terrain. Quart. J. Roy. Meteor. Soc., 137, 42-56, https://doi.org/10.1002/qj.766.

Hersbach, H., and Coauthors, 2019: Global reanalysis: Goodbye ERA-Interim, hello ERA5. ECMWF Newsletter, No. 159, ECMWF, Reading, United Kingdom, 17-24, https://doi.org/ 10.21957/vf291hehd7.
Holmes, T. R. H., R. A. M. de Jeu, M. Owe, and A. J. Dolman, 2009: Land surface temperature from $\mathrm{Ka}$ band $(37 \mathrm{GHz})$ passive microwave observations. J. Geophys. Res., 114, D04113, https://doi.org/10.1029/2008JD010257.

Houze, R. A., 2012: Orographic effects on precipitating clouds. Rev. Geophys., 50, RG1001, https://doi.org/10.1029/2011RG000365.

Hu, L., D. Deng, S. Gao, and X. Xu, 2016: The seasonal variation of Tibetan convective systems: Satellite observation. J. Geophys. Res. Atmos., 121, 5512-5525, https://doi.org/10.1002/2015JD024390.

Huffman, G. J., E. F. Stocker, D. T. Bolvin, E. J. Nelkin, and J. Tan, 2019: GPM IMERG Final Precipitation L3 1 month 0.1 degree $\times 0.1$ degree V06. Goddard Earth Sciences Data and Information Services Center, accessed 1 October 2019, https://doi.org/10.5067/GPM/IMERG/3B-MONTH/06..

Iguchi, T., and R. Meneghini, 2017: GPM DPR Precipitation Profile L2A 1.5 hours $5 \mathrm{~km}$ V06. Goddard Earth Sciences Data and Information Services Center., accessed 15 May 2018, https://doi.org/10.5067/GPM/DPR/GPM/2A/06.

Imamovic, A., L. Schlemmer, and C. Schär, 2017: Collective impacts of orography and soil moisture on the soil moistureprecipitation feedback. Geophys. Res. Lett., 44, 11 682-11 691, https://doi.org/10.1002/2017GL075657.

Immerzeel, W. W., L. P. H. van Beek, and M. F. P. Bierkens, 2010: Climate change will affect the Asian water towers. Science, 328, 1382-1385, https://doi.org/10.1126/science.1183188.

Ivanov, V. Y., S. Fatichi, G. D. Jenerette, J. F. Espeleta, P. A. Troch, and T. E. Huxman, 2010: Hysteresis of soil moisture spatial heterogeneity and the "homogenizing" effect of vegetation. Water Resour. Res., 46, W09521, https://doi.org/10.1029/ 2009WR008611.

Klein, C., D. Belušić, and C. M. Taylor, 2018: Wavelet scale analysis of mesoscale convective systems for detecting deep convection from infrared imagery. J. Geophys. Res. Atmos., 123, 3035-3050, https://doi.org/10.1002/2017JD027432.

Kottmeier, C., and Coauthors, 2008: Mechanisms initiating deep convection over complex terrain during COPS. Meteor. Z., 17, 931-948, https://doi.org/10.1127/0941-2948/2008/0348.

Kurosaki, Y., and F. Kimura, 2002: Relationship between topography and daytime cloud activity around Tibetan Plateau. J. Meteor. Soc. Japan, 80, 1339-1355, https://doi.org/10.2151/jmsj.80.1339.

Li, B., L. Yang, and S. Tang, 2019: Intraseasonal variations of summer convection over the Tibetan Plateau revealed by geostationary satellite FY-2E in 2010-14. J. Meteor. Res., 33, 478-490, https://doi.org/10.1007/s13351-019-8610-3.

Li, Y., W. Yun, S. Yang, H. Liang, S. Gao, and R. Fu, 2008: Characteristics of summer convective systems initiated over the Tibetan Plateau. Part I: Origin, track, development, and precipitation. J. Appl. Meteor. Climatol., 47, 2679-2695, https:// doi.org/10.1175/2008JAMC1695.1.

Li, Z., Z. Wei, S. Lv, W. Dong, Y. Gao, H. Wei, and Z. Zheng, 2014: Effect of land surface processes on the Tibetan Plateau's past and its predicted response to global warming: An analytical investigation based on simulation results from the CMIP5 model. Environ. Earth Sci., 72, 1155-1166, https://doi.org/ 10.1007/s12665-013-3034-3.

Liu, Y., Q. Zhu, J. Huang, S. Hua, and R. Jia, 2019: Impact of dustpolluted convective clouds over the Tibetan Plateau on downstream precipitation. Atmos. Environ., 209, 67-77, https://doi.org/ 10.1016/j.atmosenv.2019.04.001.

Meng, X., and Coauthors, 2018: Detecting hydrological consistency between soil moisture and precipitation and changes of soil moisture in summer over the Tibetan Plateau. Climate Dyn., 51, 4157-4168, https://doi.org/10.1007/s00382-017-3646-5. 
Morel, C., and S. Senesi, 2002: A climatology of mesoscale convective systems over Europe using satellite infrared imagery. I: Methodology. Quart. J. Roy. Meteor. Soc., 128, 1953-1971, https://doi.org/10.1256/003590002320603485.

NSMC, 2013: Fengyun-2 full disk cloud top temperature (CTT). China Meteorological Administration FENGYUN Satellite Data Centre, accessed 1 October 2019, https://satellite.nsmc.org.cn/ PortalSite/Default.aspx.

Owe, M., R. de Jeu, and T. Holmes, 2008: Multisensor historical climatology of satellite-derived global land surface moisture. J. Geophys. Res., 113, F01002, https://doi.org/10.1029/ 2007JF000769.

Pang, G., X. Wang, and M. Yang, 2017: Using the NDVI to identify variations in, and responses of, vegetation to climate change on the Tibetan Plateau from 1982 to 2012. Quat. Int., 444, 8796, https://doi.org/10.1016/j.quaint.2016.08.038.

Pielke, R. A., 2001: Influence of the spatial distribution of vegetation and soils on the prediction of cumulus convective rainfall. Rev. Geophys., 39, 151-177, https://doi.org/10.1029/1999RG000072.

Ramon, J., L. Lledó, V. Torralba, A. Soret, and F. J. Doblas-Reyes, 2019: What global reanalysis best represents near-surface winds? Quart. J. Roy. Meteor. Soc., 145, 3236-3251, https:// doi.org/10.1002/qj.3616.

Santanello, J. A., and Coauthors, 2018: Land-atmosphere interactions: The LoCo perspective. Bull. Amer. Meteor. Soc., 99, 1253-1272, https://doi.org/10.1175/BAMS-D-17-0001.1.

Seneviratne, S. I., T. Corti, E. L. Davin, M. Hirschi, E. B. Jaeger, I. Lehner, B. Orlowsky, and A. J. Teuling, 2010: Investigating soil moisture-climate interactions in a changing climate: A review. Earth-Sci. Rev., 99, 125-161, https://doi.org/10.1016/ j.earscirev.2010.02.004.

Sugimoto, S., and K. Ueno, 2010: Formation of mesoscale convective systems over the eastern Tibetan Plateau affected by plateau scale heating contrasts. J. Geophys. Res., 115, D16105, https://doi.org/10.1029/2009JD013609.

Taylor, C. M., 2015: Detecting soil moisture impacts on convective initiation in Europe. Geophys. Res. Lett., 42, 4631-4638, https://doi.org/10.1002/2015GL064030.

— D. J. Parker, and P. P. Harris, 2007: An observational case study of mesoscale atmospheric circulations induced by soil moisture. Geophys. Res. Lett., 34, L15801, https://doi.org/10.1029/ 2007 GL030572.

, A. Gounou, F. Guichard, P. P. Harris, R. J. Ellis, F. Couvreux, and M. De Kauwe, 2011: Frequency of Sahelian storm initiation enhanced over mesoscale soil-moisture patterns. Nat. Geosci., 4, 430-433, https://doi.org/10.1038/ngeo1173.
—, R. de Jeu, F. Guichard, P. P. Harris, and W. A. Dorigo, 2012: Afternoon rain more likely over drier soils. Nature, $\mathbf{4 8 9}$, 423-426, https://doi.org/10.1038/nature11377.

Teramura, H., T. Sato, and K. Tamura, 2019: Observed evidence of enhanced probability of mesoscale convective system initiations due to land surface heterogeneity in semiarid East Asia. SOLA, 15, 143-148, https://doi.org/10.2151/sola.2019-026.

TRMM, 2011a: TRMM Precipitation Radar Rainfall Rate and Profile L2 1.5 hours V7 (TRMM_2A25). Goddard Earth Sciences Data and Information Services Center, accessed 15 May 2018, https:// disc.gsfc.nasa.gov/datacollection/TRMM_2A25_7.html.

— 2011b: TRMM (TMPA/3B43) Rainfall Estimate L3 1 month 0.25 degree x 0.25 degree V7 (TRMM_3B43). Goddard Earth Sciences Data and Information Services Center, accessed 1 May 2020, https://doi.org/10.5067/TRMM/TMPA/MONTH/7.

Wan, W., and Coauthors, 2017: A comprehensive data set of lake surface water temperature over the Tibetan Plateau derived from MODIS LST products 2001-2015. Sci. Data, 4, 170095, https://doi.org/10.1038/sdata.2017.95.

Williams, I. N., and M. S. Torn, 2015: Vegetation controls on surface heat flux partitioning, and land-atmosphere coupling. Geophys. Res. Lett., 42, 9416-9424, https://doi.org/10.1002/2015GL066305.

Yang, K., T. Koike, H. Fujii, T. Tamura, X. Xu, L. Bian, and M. Zhou, 2004: The daytime evolution of the atmospheric boundary layer and convection over the Tibetan Plateau: Observations and simulations. J. Meteor. Soc. Japan, 82, 17771792, https://doi.org/10.2151/jmsj.82.1777.

_- and Coauthors, 2013: A multiscale soil moisture and freeze-thaw monitoring network on the third pole. Bull. Amer. Meteor. Soc., 94, 1907-1916, https://doi.org/10.1175/BAMS-D-12-00203.1.

Yu, J., T. Zhou, Z. Jiang, and L. Zou, 2019: Evaluation of nearsurface wind speed changes during 1979 to 2011 over China based on five reanalysis datasets. Atmosphere, 10, 804, https:// doi.org/10.3390/atmos10120804.

Zeng, J., Z. Li, Q. Chen, H. Bi, J. Qiu, and P. Zou, 2015: Evaluation of remotely sensed and reanalysis soil moisture products over the Tibetan Plateau using in-situ observations. Remote Sens. Environ., 163, 91-110, https://doi.org/10.1016/j.rse.2015.03.008.

Zhao, Y., X. Xu, L. Liu, R. Zhang, H. Xu, Y. Wang, and J. Li, 2019: Effects of convection over the Tibetan Plateau on rainstorms downstream of the Yangtze River Basin. Atmos. Res., 219, 24-35, https://doi.org/10.1016/j.atmosres.2018.12.019.

Zhong, L., Y. Ma, M. S. Salama, and Z. Su, 2010: Assessment of vegetation dynamics and their response to variations in precipitation and temperature in the Tibetan Plateau. Climatic Change, 103, 519-535, https://doi.org/10.1007/s10584-009-9787-8. 